reflexes, with resultant death from asphyxia. Withholding all fluids till the shock of birth is passed, the lungs more expanded and the reflexes generally better developed, has resulted in minimizing this hazard. During the past two and a half years 231 premature infants weighing between 2 and $5 \mathrm{lb}$. have been observed with regard to initial weight loss, weight gain by the third week, and the incidence of asphyctic attacks following this régime.

It was found that many infants, even in the smallest weight-groups, would go 100 or more hours before feeding was necessary. The average was 60 hours. Weight loss was the same for all weightgroups and averaged $6 \mathrm{oz}$., which represented a $14 \%$ loss in the lowest weight $\left(2-2 \frac{1}{2} \mathrm{lb}\right.$.) and $7 \%$ in the $4 \frac{1}{2}-5 \mathrm{lb}$. group. Weight gain was satisfactory with an average gain over the birth weight of $6 \frac{1}{2} \mathrm{oz}$. in all groups.

There was no evidence of any ill-effects of this régime; on the contrary, there were many benefits. Asphyxia due to fluid inhalation was abolished, oedema disappeared more quickly, and the infants were livelier when they did begin to feed.

\title{
THE BRITISH PAEDIATRIC ASSOCIATION AND THE SOCIETY OF MEDICAL OFFICERS OF HEALTH
}

A joint meeting of the British Paediatric Association and the Maternity and Child Welfare, School Health Service, and Fever Hospital groups of the Society of Medical Officers of Health was held in London on November 25-26, 1949. The meeting opened with a symposium on "The Organization of the Child Health Services.' Sir Wilson Jameson, G.B.E., K.C.B., M.D., F.R.C.P., D.P.H., was in the chair.

The Chairman prefaced the symposium by sketching the social background of paediatrics in Britain today. The findings of the Goodenough Committee had been accepted, and increased grants to medical schools should in the future enable the medical student to emerge better qualified to deal with the day-to-day care of children. Simultaneously the provisions of the National Health Service Act had brought to all mothers and children the care and guidance of a family doctor. The task now was to coordinate for their benefit the services of the family doctor, the paediatrician, and the officers of the local public health department. The part each should play was the subject of the symposium.

Dr. Helen M. M. Mackay (London) read the opening paper on 'The Organization of Child Health Services.' This paper, based on a Chadwick lecture, is published in Public Health $(63,37)$ by permission of the Chadwick Trustees. Dr. Jean Mackintosh (Birmingham) followed with a paper discussing the problem from the point of view of a maternity and child welfare officer (Public Health, 63, 41), and Dr. F. Hall (Preston) summarized the comprehensive legislation now forming the basis of a child health service and the administrative steps which should be taken to implement it. Dr. Hall's paper is published in Public Health $(63,43)$.

Professor J. C. Spence (Department of Child Health, University of Durham) chose three points on which to comment: (1) The necessity of obtaining local information and ascertaining local needs; (2) the prevention by a child health service of trauma, tuberculosis, and the acute non-specific infectious diseases, e.g. gastroenteritis; and (3) the proper use of the health visitor.

A summary of Professor Spence's address, and of the general discussion which followed, is published in Public Health $(63,61)$.

Sir Leonard Parsons, F.R.S., was the Chairman at the afternoon session when Professor A. St. G.Mc.L. Huggett delivered the George Frederick Still Memorial lecture (see p. 101).

The last sessions were devoted to scientific communications and demonstrations. The paper by Dr. J. K. Martin (London) may be found on p. $1(25,1)$ of this journal, and summaries of the following are published in Public Health, 63, 61-62.

Drs. K. U. Cross (London) on 'The Measurement of Respiration in the Newborn'; Katherine M. Hirst (London) on 'The Rising Infant Death Rate from Accidental Mechanical Suffocation '; F. J. U. Miller (Newcastle-upon-Tyne) on 'Acute Infections in Infancy '; and H. Stanley Banks (London) on 'Hyperimmune Human Serum Treatment of Whooping Cough.' 